\title{
Performance Effects of Shock Absorber and Spiral Springs Against Vertical Vehicle Expenses Weighing the Road Structure
}

\author{
Simon Ka' $\mathrm{ka}^{1, \mathrm{a}}$ and Festo Andre H., ${ }^{2, \mathrm{~b}}$ \\ ${ }^{1}$ Mechanical Engineering Department, State Polytechnic of Ujung Pandang, Jl.P.Kemerdekaan, km 10, \\ Makassar, 90245, Indonesia. \\ ${ }^{2}$ Mechanical Engineering Department, State Polytechnic of Fak-Fak, Jl.TPA Imam BonjolAtas, Fak-Fak, 92618, Indonesia. \\ ${ }^{a}$ simonkaka@poliupg.ac.id \\ bfestoandrehardinsi@yahoo.com
}

Abstract - This study aims to examine more about the effect of vertical dynamic load of vehicles and changes in dimensional barriers on the road surface in its path. Experimentally this fluctuating load is replaced by a pneumatic force change based on the regulation of air pressure on the regulator. The deviations generated by the varying load work are measured by placing a proximity sensor along the spring movement. The amount of vertical load transformation reaches the road surface is measured by using Load cell. Characteristics of vertical dynamic vibration occurring due to several dimensional barriers, $U(\mathbf{c m})$ obtained using mathematical modeling method with 2 DOF suspension system transfer function. The results showed a condition on the body and wheels of vehicles experienced a brief overshot for 0.14 seconds with deviation of $0.178 \mathrm{~m}$. From the graph shows that the rate of deviation that occurs is large enough that $\mathrm{Y} 2 \mathrm{~d}=1.03 \mathrm{~m} / \mathrm{s}$ caused by a sudden shock that occurred on the wheels of the vehicle. This condition does not last long that is only duration $t=0.22 \mathrm{~s}$, because the spring reaction force and shock absorber can absorb $25 \%$ vibration against the sprung and un-sprung vertical load of the vehicle.

Keywords: shock absorber, load fluctuation, pneumatic force, spiral springs, vertical load

\section{Introduction}

The increasing volume of vehicles, especially fourwheel vehicles passing through roads, will decrease the ability of road structures to support vehicle vertical loads. Vibrations originating from vertical dynamic loads of vehicles often fluctuate due to unstable drivers and passengers. Such conditions will further weaken the ability of the road structure to accept the fluctuating load. The spring and shock absorber mounted on each of the wheels of the vehicle is expected to be able to overcome and reduce the vertical dynamic load of vehicles overloading the road structure. The vehicle suspension system according to $[1,2]$ is composed of a spring and a shock absorber arranged in parallel. The main function of the suspension system is to support the weight of the vehicle, to provide comfort for the rider, to keep traction of the wheel on the road surface condition, and to maintain the alignment of the front wheel and rear wheel [3-5]. The shape and mechanism of the suspension system is shown in Fig. 1(a), with sprung mass $\left(\mathrm{m}_{2}\right)$, un-sprung mass $\left(\mathrm{m}_{1}\right)$, suspension spring $\left(\mathrm{k}_{2}\right)$, shock absorbers (c) and tire elastic constants on wheels $\left(\mathrm{k}_{1}\right),[6,7]$.

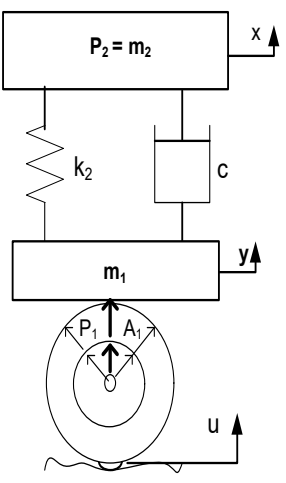

(a)

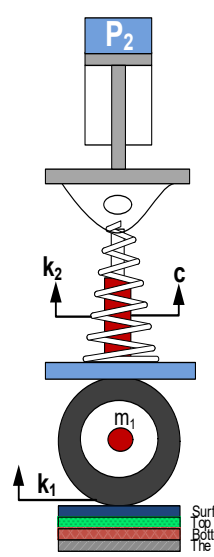

(b)

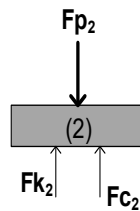

$\mathrm{Fr}_{1} \mathrm{Fp}_{2}$

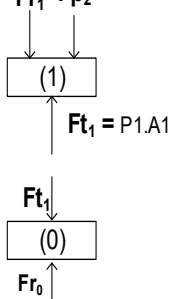

(c)
Fig. 1. (a) Sprung mass and Un-sprung mass, (b) Pneumatic system experiments, (c) Free body diagram

The magnitude of the pneumatic cylinder thrust force from equation (1) to equation (4) generated by the air pressure $\mathrm{P}_{2}$ (bar) according to $[6,8]$ are formulated as;

$$
F_{k}=\frac{\pi}{4} D^{2} P_{2}(\mathrm{~N})
$$


If the dimensions of the cylinder, $\mathrm{D}=100 \mathrm{~mm}(0.100 \mathrm{~m})$ are substituted to equation (1) then the compression force of the suspension mechanism is obtained:

$$
\begin{array}{r}
F_{k}=785 \times P_{2} \text { and } \\
F_{p 2}=706.5 P_{2}=707 P_{2}(\mathrm{~N}) .
\end{array}
$$

Based on the free-body diagram of Fig. 1 (c), the equation of the wheel loading the road structure is;

$$
\left.\begin{array}{c}
F_{t 1}=F_{p 2}+F_{r 1} \\
F_{t 1}=\left(k_{2}+c\right) x_{2}+\left(m_{1} \cdot g\right)
\end{array}\right\}
$$

If in equation (3), the spring constant $\mathrm{k}_{2}(\mathrm{~N} / \mathrm{mm})$, the coefficient of damping c $(\mathrm{Ns} / \mathrm{mm})$, the weight of the wheel $\mathrm{m}_{1}(\mathrm{~kg})$ and the gravitational acceleration $\mathrm{g}\left(\mathrm{m} / \mathrm{s}^{2}\right)$ are obtained;

$$
F_{t 1}=F_{r o}=707 P_{2}+\left(m_{1} \cdot g\right)(\mathrm{N})
$$

The mass sprung of $\mathrm{m}_{2}$ supported by the spring and the shock absorber with the spring stiffness of $\mathrm{k}_{2}$ and the damping coefficient $\mathrm{c}$ will overload the vehicle wheel as the mass unsprung of $m_{1}$ further gives the action force to the contour of the road surface[18]. The reaction force of the road contour to the tire will be distributed in the direction of $\mathrm{u}$ through the tire elasticity constant of $\mathrm{k}_{1}$. Thus the transfer function of a quarter vehicle suspension system for a front wheel with two degrees of freedom (2DOF) is obtained by comparing the output and input as follows:

$\frac{Y(s)}{U(s)}=$

$\frac{k_{1}\left(c s+k_{2}\right)}{m_{1} m_{2} s^{4}+\left(m_{1}+m_{2}\right) c s^{3}+\left[k_{1} m_{2}+\left(m_{1}+m_{2}\right) k_{2}\right] s^{2}+k_{1} c s+k_{1} k_{2}}$

Calculation of spring constant value, $\mathrm{k}_{2}$ by[9-11] respectively in the book "Machinery's Handbook, $29^{\text {th }}$ Edition and the journal Mechanism and Machine Theory are formulated as follows:

$$
k_{2}=\frac{G d^{4}}{8 n_{a} D^{3}}
$$

$G$ is the modulus of stiffness $\left(\mathrm{N} / \mathrm{cm}^{2}\right), d$ is the diameter of the wire $(\mathrm{cm}), n_{a}$ is the number of active coils and $D$ is the mean coil diameter $(\mathrm{cm})$ obtained from the difference between the outer diameter of the coil and the diameter of the wire. The number of active coils, $n_{a}$ is usually less than the total coil, $\mathrm{n}$ whereas the spring compress area is between the minimum compression of
$20 \%$ and the maximum compression of $80 \%$. If the number of active coils, $\mathrm{n}_{\mathrm{a}}=80 \% \mathrm{x} \mathrm{n}$, and the mean coil diameter, $\mathrm{D}=\mathrm{Do}-\mathrm{d}$ then the value of the spring constant, $\mathrm{k}_{2}$ can be obtained by using equation (6). Mathematical modeling of the working mechanism of the spring and shock absorber is used by [5] to prove that the greatest vibrations occur due to the un-sprung weight of the vehicle.

\section{Research Methodology}

\section{A. Experimental Setup}

Experimental tests conducted on the mechanical work of suspension on the wheels of the vehicle is by adjusting the working pressure $\mathrm{P}_{2}$ (bar) on the regulator ranging from 1 to 8 bar [6]. Furthermore, the loading of the spring and the shock absorber by the pneumatic actuator begins to occur when the $5 / 2$ directional control valve is operated. The dimensions of the Pneumatic actuator and the $5 / 2$ directional control valve used at the working pressure, $\mathrm{P}=6$ (bar) are as follows;

The type of pneumatic cylinder selected is, DNU100-300-PVA and sourced from [12] with specifications; Diameter of piston $\mathrm{D}=100 \mathrm{~mm}$, stroke $\mathrm{L}=300 \mathrm{~mm}$, Weight piston $\mathrm{W}=3.864 \mathrm{~kg}=38.64 \mathrm{~N}$, and Weight piston rod $/ 10 \mathrm{~mm} \mathrm{w}=0.090 \mathrm{~kg}$. The forward and reverse thrust force of cylinder piston at a working pressure of 6 bar are respectively $F_{k}=4496 \mathrm{~N}$ and $F_{m}=$ $4221 \mathrm{~N}$, piston weight, $\mathrm{W}=3.864 \mathrm{~kg}=38.64 \mathrm{~N}$ Weight $/ 10 \mathrm{~mm}$ and piston rod, $\mathrm{w}=0.090 \mathrm{~kg} / 10 \mathrm{~mm}$.

The change in the position of compression motion on the spring and the shock absorber is measured by placing the proximity sensor along the spring movement. The amount of deviation detected by the sensor can be transferred to the LCD in digital form. It should be noted that the change in the size of the readings on the LCD screen is correlated with the regulatory pressure settings. By placing a Load cell gauge just below the wheel of the vehicle, the measurement of the vertical dynamic load of the vehicle successfully transformed to the road surface can be obtained through a direct reading on the LCD screen.

Optimization of physical models, using pneumatic cylinders as dynamic vertical drive test simulators on wheel drive suspension work has been discussed by [6, 13]. Mathematical model optimization is done by making the weight data of wheel axis, $\mathrm{m}_{1}(\mathrm{~kg})$ and body weight, $\mathrm{m}_{2}(\mathrm{~kg})$ as INPUT as shown in Figure 2.1 (b). Similarly, the constant values of $\mathrm{k}_{1}, \mathrm{k}_{2}$, and $\mathrm{c}_{2}$ are the input data to create the program in Mat Lab.

The test spring used in the suspension system mechanism is a kind of "Helical" with the following 
specifications: inside and outside coil diameters are $\mathrm{Di}=$ $12.985 \mathrm{~cm}$ and Do $=15.815 \mathrm{~cm}$, diameter of spring wire, $\mathrm{d}=1.415 \mathrm{~cm}$, and number of coils, $\mathrm{n}=5$ pieces. The spring material used is from Chrome Vanadium, ASTM A231 with Stiffness Modulus, $\mathrm{G}=7.929 \mathrm{E}+10 \mathrm{~Pa}=$ $7.929 \times 10^{6} \mathrm{~N} / \mathrm{cm}^{2}$. Analysis of the same type of spring above is utilized by $[14,15]$ to improve shock absorber function to absorb motion energy.

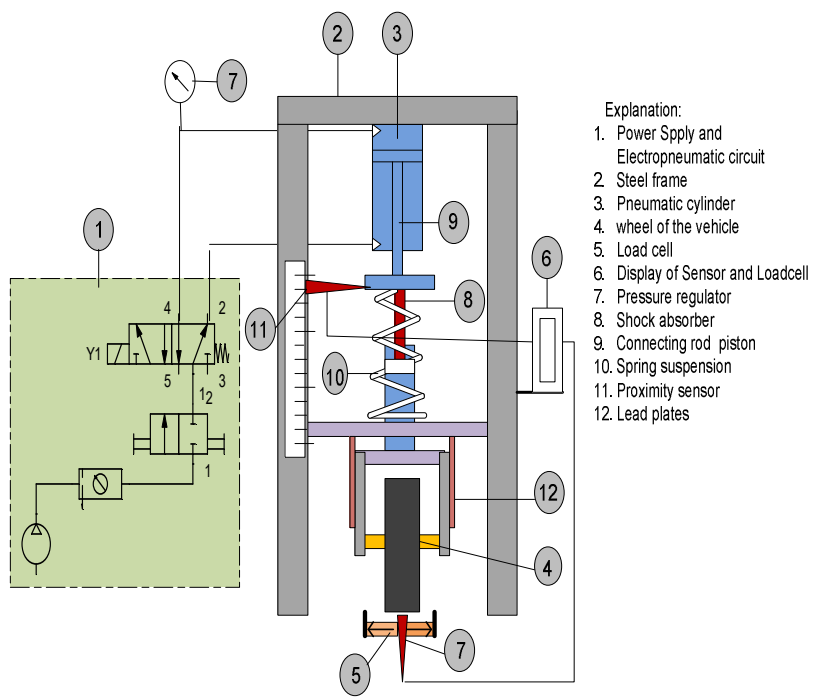

(a)

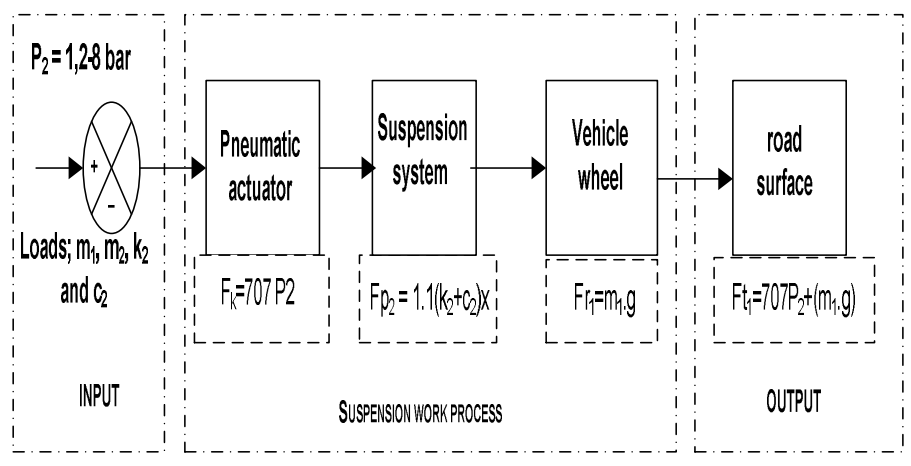

(b)

Fig. 2 (a) Loading experiments with pneumatic actuators, (b) Block diagram of vehicle suspension loading process.

\section{B. Population and Sample}

The population of the targeted vehicle is the medium category vehicles including Terios, New Rush, Suzuki R3, Grand Max, Suzuki APV, Isuzu D-Max pickup until Fortuner car. The sample selection of medium weight vehicles is shown in Table 1, each of which is randomly performed. A number of vehicles belonging to the medium weight category, Terios is one medium- weighted vehicle with a net weight of $m_{2}=1665 \mathrm{~kg}$ and axis weight, $\mathrm{m}_{1}=600 \mathrm{~kg}$, then selected as research sampling, representing the population of other vehicle types.

Table 1. Vehicle Data With Medium Weight Categories.

\begin{tabular}{lllccc}
\hline & & \multicolumn{3}{c}{ Vehicle Weight (kg) * } \\
\cline { 3 - 6 } No. Vehicles & $\begin{array}{c}\text { Body } \\
\mathrm{m}_{2}\end{array}$ & $\begin{array}{c}\text { Total/N } \\
\text { etm2 }\end{array}$ & $\begin{array}{c}\text { Maxim } \\
\text { um } \\
\mathrm{m}_{2}\end{array}$ & $\begin{array}{c}\text { wheel } \\
\text { axis } \\
\mathrm{m}_{1}\end{array}$ \\
\hline 1 & Terios & 1235 & 1665 & & 600 \\
2 & New Rush & 1950 & 2510 & & 600 \\
3 & PickUp, & 1950 & 2510 & 600 \\
& Grandma & & & & \\
& x & & & & \\
4 & Suzuki R3 & 1185 & 1745 & & 600 \\
5 & Suzuki & 1950 & 2510 & & \\
& APV & & & & \\
6 & Isuzu D- & 1990 & 2550 & 2550 & \\
& max, & & & & \\
& Pick up & & & & \\
\hline
\end{tabular}

* P.T. Astra Internasional, Tbk. Indonesia

\section{Data Collection}

Procedures and steps taken on primary data retrieval activities are:

1) Collect medium-weighted vehicle data $\left(M_{2}\right)$ which has axle weight, $\mathrm{m}_{1}(\mathrm{~kg})$ and body weight $\mathrm{m}_{2}(\mathrm{~kg})$ as in Table 1, relevant journals, books, and other references.

2) Calculating the spring stiffness factor $\mathrm{k}_{2}$, damping value, $c_{2}$ and wheel specifications in each vehicle type either obtained from reference journal or through calculation.

3) Conducting experimental and observation activities directly by operating the motion simulation test equipment as follows; Prepares the pressurized air on the air service unit while adjusting the working pressure on the regulator starting from $\mathrm{P} 2=1$ bar to 8 bar.

4) Operate the actuator lever on the $5 / 2$ direction control valve by turning the lever towards the cylinder piston movement, up and down. When the cylinder piston moves down, the loading process will occur in the spring and shock absorber in the compression direction.

The drift, $x(\mathrm{~mm})$ that occurs due to loading, the magnitude can be read on the available digital display ranging from 0 to $60 \mathrm{~mm}$ by the proximity sensor. It should be noted that the magnitude of the deviation is highly correlated with the pressure setting on the Manometer. 
Moving time, $\mathrm{t}(\mathrm{s})$ can be measured using a stopwatch when there is a drift from $\mathrm{x}_{0}$ to $\mathrm{x}(\mathrm{mm})$. The amount of vertical load that reaches the road surface can be measured by placing "Load cell" just below the wheel of the vehicle.

\section{Results and Discussion}

Programming with Mat Lab software referring to equation (2.3) will produce the suspension vibration characteristics with small and large deviations as shown in Fig. 3 (a), (b) and (c). The execution result of the program has obtained the characteristic graph of vibration on the suspension as the impact of vertical dynamic load. In Fig. 3. (a), if the INPUT resistance is $\mathrm{U}=0.1 \mathrm{~m}$, then the suspension on the wheels will experience vibration with maximum deviation, $\mathrm{Y}=0.188 \mathrm{~m}$ with a vibration time of $0.339 \mathrm{~s}$. then two seconds later, the minimum deviation occurs at $\mathrm{Y}=0.101 \mathrm{~m}$. Proportionally author [16] has obtained $0.12 \mathrm{~m}$ deviation on the measured vehicle wheel as a strain using the WIM sensor that placed below the tire.

The characteristic shape of the vibration in the wheel suspension as in Fig. 3 (a) is caused by a mound as high as $U=0.1(\mathrm{~m})$ on the road surface. Similarly, the reaction to the total dynamic load of the vehicle can result in a vertical overshot deviation of $\mathrm{Y}=0.188(\mathrm{~m})$ with a duration of 0.1 seconds. Furthermore, within a time interval of 2.34 seconds later, the vibrations begin to shrink and stabilize at 0.66 seconds.

The result of the research in Fig. 3 (b) shows that the largest deviation rate occurs at $\mathrm{Y} 2 \mathrm{~d}=1.03 \mathrm{~m} / \mathrm{s}$ when $\mathrm{t}=0.22 \mathrm{~s}$, while the lowest deviation rate is $\mathrm{Y} 2 \mathrm{~d}=0.02$ $\mathrm{m} / \mathrm{s}$ when the vibration time $\mathrm{t}=2.65 \mathrm{~s}$. From the graph shows that the rate of deviation that occurs largely enough caused by a sudden shock that occurs on the wheel. Such conditions can not last long because of the resistance of the spring and shock absorber.

The change in the drift velocity shown in Fig. 3 (c) has a significant slowdown of $\mathrm{Y} 2 \mathrm{dd}=(-10.9+8.41) \mathrm{m} /$ $\mathrm{s}=-2.59 \mathrm{~m} / \mathrm{s}^{2}$ at $\mathrm{t}=0.301 \mathrm{~s}$. The maximum vibration acceleration produced by sprung and un-sprung masses occurs at frequencies $1.0 \mathrm{~Hz}$ and $9.1 \mathrm{~Hz}$ [5].

It should be noted that the perceived comforts of the vehicle are often disrupted by the uneven, hollow, bumpy surface of the road surface and are filled with mound-shaped materials. Comfort can also be felt by passengers and drivers when the mechanism of shock absorber damper is able to reduce vertical dynamic load of the vehicle well.

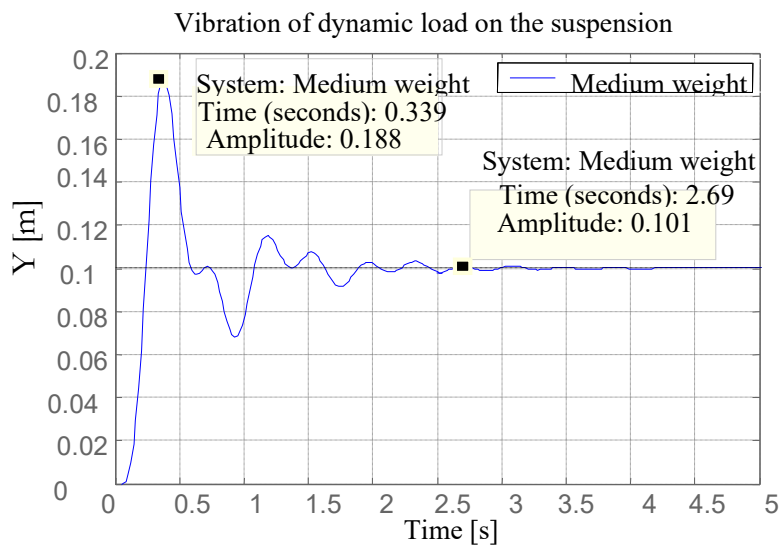

(a)

Vibration velocity

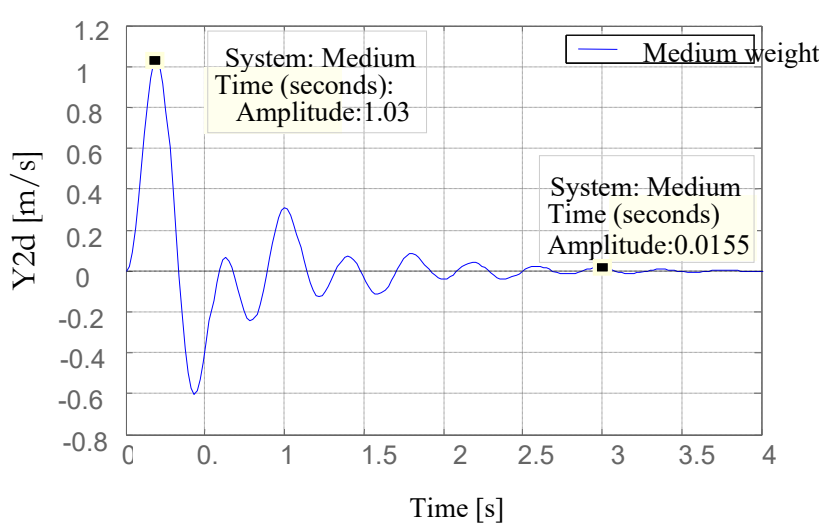

(b)

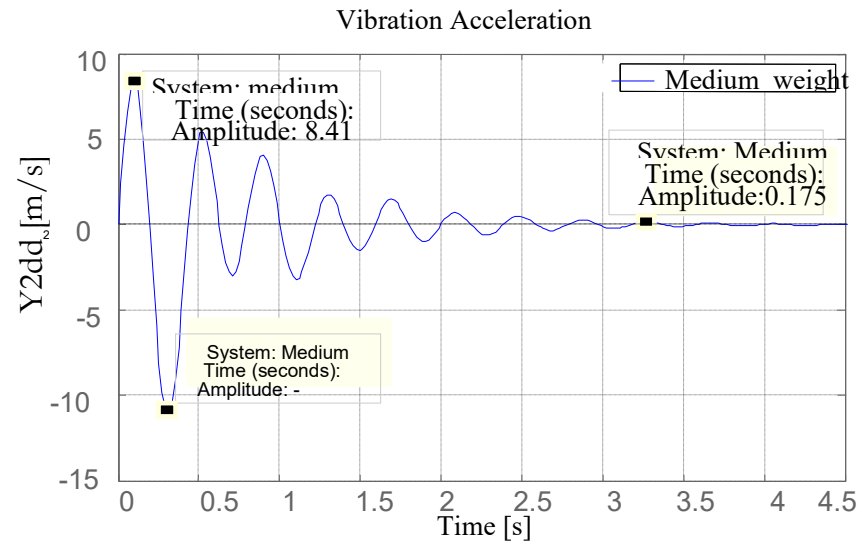

(c)

Fig. 3. (a) Characteristics of vibration on the body and wheels with deviation $\mathrm{Y}(\mathrm{m})$, (b) The characteristics of vibration velocity on the body and wheels, $\mathrm{V}(\mathrm{m} / \mathrm{s})$, (c) The characteristics of vibration acceleration on the body and wheels, a $\left(\mathrm{m} / \mathrm{s}^{2}\right)$. 
If the circulation of liquid or gaseous fluid determined by the regulation of the flow control valve in the cylinder chamber, the performance of the absorbent shock is getting better.

The amount of deviation experienced by the body and the vehicle's axle while experiencing vertical dynamic loads of experimental results and modeling using Mat Lab due to shown in Fig. 3.

The comparison of deviation values between the experimental results and the programming with Mat-Lab is shown in Table 2.

Table 2. Characteristics of Experimental Results and Theoretical Deviation

\begin{tabular}{ccccc}
\hline Pressure & \multicolumn{2}{c}{ Experimental } & \multicolumn{2}{c}{ Theoretical } \\
P1(bar) & $\mathrm{t}(\mathrm{s})$ & $\mathrm{Y}(\mathrm{m})$ & $\mathrm{t}(\mathrm{s})$ & $\mathrm{Y}(\mathrm{m})$ \\
\hline 1 & 0.5 & 0.059 & 0.5 & 0.11 \\
2 & 1.0 & 0.067 & 1 & 0.087 \\
3 & 1.6 & 0.078 & 1.5 & 0.11 \\
4 & 2.1 & 0.086 & 2 & 0.1 \\
5 & 2.7 & 0.088 & 2.5 & 0.098 \\
6 & 3.3 & 0.092 & 3 & 0.1 \\
7 & 3.9 & 0.096 & 3.5 & 0.1 \\
8 & 4.6 & 0.098 & 4 & 0.099 \\
\hline
\end{tabular}

Vibration characteristic of Experiment Vs Theoretical

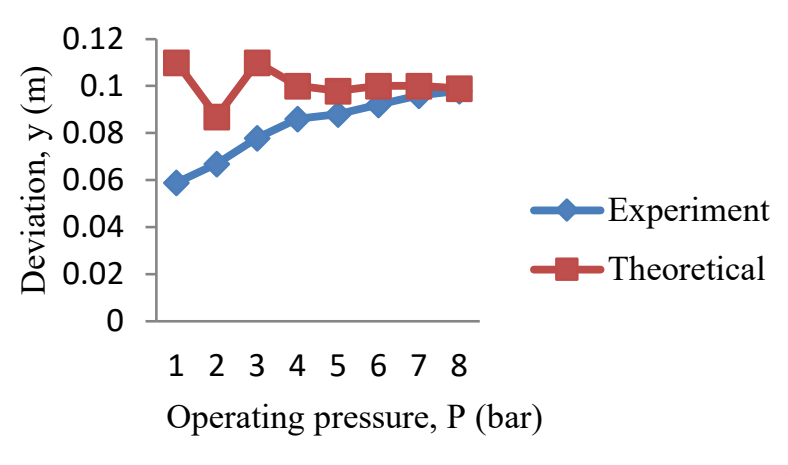

Fig. 4. Relationship of vibration characteristics between experimental and theoretical studies.
The experimental vibration characteristics and theoretical studies as shown in Fig. 4, shows a trend that starting at the working pressure of 4 bars vibration deviation is increasingly blessing each other and finally at the working pressure of 8 bars the deviation is at $\mathrm{Y}=$ $0.1 \mathrm{~m}$.

The mean deviation of the experimental results is $\mathrm{Y}=$ $0.083 \mathrm{~m}$, with a mean duration of $2.5 \mathrm{~s}$, while the average deviation of the programming results is $\mathrm{Y}=0.1$ $(\mathrm{m})$ in the mean duration, $\mathrm{t}=4.5 \mathrm{~s}$.

The rate of deviation and the acceleration of movement of the vehicle body that weighs $300 \mathrm{~kg}$ by [3] are $0.03 \mathrm{~m}$ and $1.8 \mathrm{~m} / \mathrm{s}^{2}$ respectively and stabilized at $\mathrm{t}=3.5(\mathrm{~s})$.

The shape of the deviation graph shows that at the time of vibration, $\mathrm{t}=0.5 \mathrm{~s}$ there is a deviation gap of $\mathrm{Y}=0.051 \mathrm{~m}$, when pressure $\mathrm{P}=1 \mathrm{bar}$, but after reaching the vibration time $t=2.1 \mathrm{~s}$ when pressure $\mathrm{P}=4 \mathrm{bar}$, then the deviation gap starts to decrease to $\mathrm{Y}=0.014 \mathrm{~m}$.

\section{Conclusion}

Based on the results of experimental studies and analyzes that have been done on the vehicle suspension work performance, it can be concluded as follows:

1 Characteristics of the working mechanism of the suspension on the body and wheels of the vehicle for the type of medium weight vehicle if experiencing the disturbance $\mathrm{U}=0.1 \mathrm{~m}$ it will happen the largest deviation $\mathrm{Y}=0.18 \mathrm{~m}$ with a duration of 0.1 seconds. Within a span of 2.34 seconds later, the vibrations begin to shrink and eventually stabilize at 0.66 seconds.

2 Characteristics of suspension vibration rate on the largest vehicle wheels occur at $\mathrm{Y} 2 \mathrm{~d}=1.03 \mathrm{~m} / \mathrm{s}$ when $\mathrm{t}=0.22 \mathrm{~s}$, while the lowest deviation rate is $\mathrm{Y} 2 \mathrm{~d}=$ $0.02 \mathrm{~m} / \mathrm{s}$ when the vibration time $\mathrm{t}=2.65 \mathrm{~s}$.

3 The occurrence of change in deviation speed at the work of the suspension will reduce the driving comfort felt directly by the passengers and drivers. 


\section{Acknowledgement}

Authors would like to thank to Kemenristekdikti, supervising commission team, Mechatronics Study Program of State Polytechnics of Ujung Pandang, which have much support and facilitate the authors in the form of grants, guidance, and support of laboratory equipment and workshops.

\section{References}

[1] M. F.-D. J. Brembeck, "LPV Control of Full-Vehicle Vertical Dynamics using Semi-Active Dampers," Science Direct, vol. 49-11, p. 8, 2016.

[2] M. A. A. Mohd Nizam Sudin1, Shamsul Anuar Shamsuddin1, Faiz Redza Ramli1, Musthafah Mohd Tahir1, "Review of Research on Vehicles Aerodynamic Drag Reduction Methods," Review of Research on Vehicles Aerodynamic Drag Reduction Methods, vol. Vol.14, p. 35, 2014.

[3] M. TongyiXu,ChuanLi, ShuaiYang, "Design and analysis of a shock absorber with variable moment of inertia for passive vehicle suspensions," Journal of Sound and Vibration, vol. 355, p. 20, 2015.

[4] E. A. Finney, "Dynamic Aspect Of Vehicle Size and Weight," p. 23, 2010.

[5] W. H. Tan, "Vibration analysis on compact car shock absorber," Journal of Physics: Conference Series, vol. 908, 2017.

[6] Simon Ka'ka' Syukri Himran, Ilyas Renreng and Onny Sutresman, "Pneumatic Actuator As Vertical Dynamic Load Simulator On The Suspension Mechanism Of A Quarter Vehicle Wheels," ARPN Journal of Engineering and Applied Sciences, vol. 12, 2017.

[7] X. J. Y. Z. W. Ma, "Nonlinear dynamic characteristics of a micro-vibration fluid viscous damper," Springer Science+Business Media, B.V., vol. 92, p. 10, 2018.

[8] Simon Ka'ka ${ }^{1,}$ Syukri Himran ${ }^{2}$, Ilyas Renreng ${ }^{2}$ and Onny Sutresman", "The Pneumatic Actuators As Vertical Dynamic Load Simulators On Medium Weighted Wheel Suspension Mechanism," Journal of Physics, vol. 962, p. 10, 2018.
[9] E. Edge, "Helical Compression Spring Design Equation and Calculator," Became An Engineers Edge Contributor, 2017.

[10] P.-A. Y. Hassen Trabelsi, Jamel Louati, Mohamed Haddar "Interval computation and constraint propagation for the optimal design of a compression spring for a linear vehicle suspension system," Mechanism and Machine Theory, journal homepage: www.elsevier.com/locate/mechmt, vol. 48, pp. 67-89, 2015.

[11] A. W. Moore, "Regression and Classification with Neural Networks," vol. 412-268-7599, 2003.

[12] K. Festo, "Automation With Pneumatic," in Festo Didactic, KG vol. NR.23099-01/1, ed. Esslingen: Festo Pneumatic, 2015.

[13] L. D. Y. A. Asst. prof. Munaf F. Badr, Ahmed Kadhiam Jaliel, "Position Control of the Pneumatic Actuator Employing ON/OFF Solenoids Valve," International Journal of Mechanical \& Mechatronics Engineering IJMME-IJENS, vol. Vol.17 No.02, p. 9, 2016.

[14] D. J. Johnson, Anthony Tony, "Design And Analysis Of A Shock Absorber," International Journal of Scientific \& Engineering Research, vol. 7, p. 5, 2016.

[15] S. W. B. G.R. Chavhan, Dr.L.P.Dhole, "Analysis Of Shock Absorber Using Different Material Of Spring," International Journal of Advanced Engineering Technology, vol. V, pp. 19-21, 2014.

[16] Wenbin Zhang 1, Chunguang Suo and Qi Wang, "A Novel Sensor System for Measuring Wheel Loads of Vehicles on Highways," Sensors www.mdpi.com/journal/sensors, vol. 8, p. 19, 2008.

[17] D. B. Manjunatha.T.R H.V. Prabhunanand G.R, Chavhan"Design and Static Structural Analysis of Cylinder and Piston of Two Stage Reciprocating Compressors Using ANSYS," International Journal of Innovative Research in Science, Engineering and Technology (An ISO 3297: 2007 Certified Organization), vol. Vol. 2, p. 7, 2013.

[18] S. Ka'Ka, S. Himran, I. Renreng, and O. Sutresman, "Modeling of Vertical Dynamic Vibration Characteristics on Vehicles Suspension System," IOP Conf. Ser. Mater. Sci. Eng., vol. 619, no. 1, 2019, doi: 10.1088/1757-899X/619/1/012003. 